INPLASY

PROTOCOL

To cite: Torres et al. Spiritual

Care Competency in Nursing:

An Integrative Literature

Review Protocol. Inplasy protocol 2021110081. doi:

10.37766/inplasy2021.11.0081

Received: 22 November 2021

Published: 22 November 2021

Corresponding author:

Claudia Consuelo Torres

Contreras

ctorres67@unisalle.edu.co

Author Affiliation:

Universidad de la Salle

Support: None.

Review Stage at time of this submission: Preliminary

searches.

Conflicts of interest:

None declared.

\section{Spiritual Care Competency in Nursing: An Integrative Literature Review Protocol}

Torres, CC1; Vargas, LM²; Triana, JY3; Cañon-Montañez, W4.

Review question / Objective: To review studies with perspectives and intervention strategies for the formation and education in spiritual care for both professionals and nursing students.

Condition being studied: Development of empirical studies in the field of nursing education that allow to visualize the developments in the formation of competence in spiritual care, investigating the educational interventions and pedagogical strategies implemented in the formation of nursing professionals and nurses in this specific field.

Information sources: Electronic databases: Medline (via PubMed), ProQuest (via EBSCO), Scopus, LILACS and BDENF (via Biblioteca Virtual en Salud - BVS) and SciELO. Scopus, Medline (via PubMed) and LILACS.

INPLASY registration number: This protocol was registered with the International Platform of Registered Systematic Review and Meta-Analysis Protocols (INPLASY) on 22 November 2021 and was last updated on 22 November 2021 (registration number INPLASY2021110081).

\section{INTRODUCTION}

Review question / Objective: To review studies with perspectives and intervention strategies for the formation and education in spiritual care for both professionals and nursing students.
Condition being studied: Development of empirical studies in the field of nursing education that allow to visualize the developments in the formation of competence in spiritual care, investigating the educational interventions and 
pedagogical strategies implemented in the formation of nursing professionals and nurses in this specific field.

\section{METHODS}

Search strategy: The search was carried out in the databases: Medline (via PubMed), ProQuest (via EBSCO), Scopus, LILACS and BDENF (via Biblioteca Virtual en Salud BVS) and SciELO. The following descriptors, terms and keywords will be combined for the search strategy: Spiritually, Holistic Nursing, Education, Nursing, Educations Nursing, Nursing Educations, Nursing Education Research.

Participant or population: Nursing students and nursing professionals.

Intervention: Studies with an educational/ pedagogical intervention component in spiritual care.

Comparator: Control group or usual care.

Study designs to be included: Studies with educational interventions in spiritual care.

Eligibility criteria: We will included studies with educational interventions in spiritual care in nurses or nursing students, developed during the years 2001 to 2021 and published in English, Spanish and Portuguese languages. Studies of educational interventions in spiritual care in students of professions other than nursing will be excluded.

Information sources: Electronic databases: Medline (via PubMed), ProQuest (via EBSCO), Scopus, LILACS and BDENF (via Biblioteca Virtual en Salud - BVS) and SciELO. Scopus, Medline (via PubMed) and LILACS.

Main outcome(s): Spiritual care competence.

Data management: The following variables will be extracted from the studies: pedagogical strategy used in the intervention, number of educational sessions carried out, country, population, authors, conceptual elements related to spirituality and spiritual care.

Quality assessment / Risk of bias analysis: The methodological quality of studies will be assessed using the Eligibility Criteria Instrument for the Selection of Research Articles (ICrESAI), to determine the selection, scientific merit and quality of the articles eligible to be part of the review.

Strategy of data synthesis: Studies with interventions focused on spiritual care competency and that had an educational and/or pedagogical component have been proposed with favorable results in terms of strengthening spiritual care in nursing professionals and students.

Subgroup analysis: Not applicable.

Sensitivity analysis: Not applicable.

Country(ies) involved: Colombia.

Keywords: Spiritually, Holistic Nursing, Nursing Educations, Nursing Education Research.

Contributions of each author:

Author 1 - Claudia Torres Contreras.

Email: ctorres67@unisalle.edu.co Author 2 - Lina María Vargas Escobar.

Email: Imvargase@unbosque.edu.co Author 3 - Jorge Yecid Triana Rodríguez.

Email: jytriana@unisalle.edu.co Author 4 - Wilson Cañon-Montañez. Email: wilson.canon@udea.edu.co 